\title{
A Aprendizagem Cooperativa como metodologia ativa no Ensino Médio: Percepção de alunos de uma escola pública da Cidade de Milagres, Ceará
}

Cooperative Learning as an active methodology in High School: Perception of students from a public school in the City of Milagres, Ceará

El aprendizaje cooperativo como metodología activa en el Bachillerato: Percepción de alumnos de un colegio público de la Ciudad de Milagres, Ceará

Ramira Araújo Rodrigues Silva ORCID: https://orcid.org/0000-0002-8284-7023 Universidade Regional do Cariri, Brasil E-mail: ramiraaraujo70@gmail.com Dennis Bezerra Correia ORCID: https://orcid.org/0000-0002-7782-4767 Universidade Regional do Cariri, Brasil E-mail: denniscorreia40@gmail.com

Bruna Barbosa Dias Ferreira Amaro ORCID: https://orcid.org/0000-0003-1255-2622 Universidade Regional do Cariri, Brasil E-mail: brunnabarbosadyas@gmail.com

Maria Sanadia Alexandre da Silva ORCID: https://orcid.org/0000-0003-3647-055X Universidade Regional do Cariri, Brasil E-mail: sanadiaalexandre@gmail.com

Mikaella Batista Queiroz

ORCID: https://orcid.org/0000-0002-4223-1814 Universidade Regional do Cariri, Brasil E-mail: batistamikaella05@gmail.com

Leonardo Alves de Lima

ORCID: https://orcid.org/0000-0003-1295-6088 Universidade Regional do Cariri, Brasil

E-mail: leooliimaa1@gmail.com

Luiz Neldecílio Alves Vitor

ORCID: https://orcid.org/0000-0003-4085-4214 Secretaria de Educação e Esportes de Pernambuco, Brasil

E-mail: professorluizneldecilio@gmail.com

Rafael Henrique Luciano dos Santos

ORCID: https://orcid.org/0000-0001-6968-6803 Secretaria de Educação e Esportes de Pernambuco, Brasil E-mail: rafaelhenrique.bio@gmail.com

Cícero Jorge Verçosa

ORCID: https://orcid.org/0000-0002-3284-6719 Secretaria de Educação e Esportes de Pernambuco, Brasil

E-mail: cjvercosa@hotmail.com

Maria Eliana Vieira Figueroa

ORCID: https://orcid.org/0000-0002-0049-4456 Secretaria de Educação e Esportes de Pernambuco, Brasil E-mail: elianavfigueroa1@gmail.com

Clêidio da Paz Cabral

ORCID: https://orcid.org/0000-0003-1825-4925 Secretaria de Educação e Esportes de Pernambuco, Brasil

E-mail: cabralbahia@hotmail.com

Marcos Aurélio Figueiredo dos Santos

ORCID: https://orcid.org/0000-0002-3409-5242 Universidade Regional do Cariri, Brasil E-mail: marcos.figueiredo@urca.br Francileide Vieira Figueirêdo

ORCID: https://orcid.org/0000-0002-6853-854X Universidade Regional do Cariri, Brasil E-mail: francileidevf@gmail.com 


\author{
João Paulo Camilo de Oliveira \\ ORCID: https://orcid.org/0000-0003-0286-1149 \\ Universidade Regional do Cariri, Brasil \\ E-mail: camilodeoliveirajoaopaulo35@gmail.com \\ Cicero Magerbio Gomes Torres \\ ORCID: https://orcid.org/0000-0002-3585-452X \\ Universidade Regional do Cariri, Brasil \\ E-mail: cicero.torres@urca.br \\ Elaine Cristina Conceição de Oliveira \\ ORCID: https://orcid.org/0000-0002-2593-4390 \\ Universidade Regional do Cariri, Brasil \\ E-mail: elainecryca@hotmail.com
}

\begin{abstract}
Resumo
É indiscutível a necessidade em desenvolver metodologias de ensino que sejam, de fato, eficientes para a construção do saber. Nesta perspectiva, encontra-se na literatura indicações de que a metodologia da aprendizagem cooperativa se configura como uma alternativa viável, que contribui para uma maior interação entre os envolvidos e o desenvolvimento de competências sociais e cognitivas. Dessa forma, este trabalho tem como objetivo analisar a percepção de alunos do ensino médio em relação às contribuições da referida metodologia, delineando os pontos positivos e negativos da mesma. A coleta de dados se deu pela aplicação de questionários previamente estruturados obedecendo aos critérios éticos da pesquisa, em turmas de $1^{\circ}$ e $3^{\circ}$ ano, compreendendo uma amostra de 42 alunos, cuja participação ocorreu de forma voluntária. Os resultados obtidos evidenciam que a grande maioria dos alunos se posiciona a favor da metodologia de ensino em questão, classificando-a como determinante para seu processo de aprendizagem, uma vez que melhora o rendimento escolar e promove a socialização do conhecimento. Conclui-se, portanto, que apesar dos problemas citados por alguns alunos, a utilização da metodologia cooperativa promove uma maior interação entre os alunos, apresentando resultados significativos no aumento do rendimento escolar e na aquisição de habilidades sociais.
\end{abstract}

Palavras-chave: Metodologia ativa; Ensino-aprendizagem; Discentes; Aprendizagem cooperativa.

\begin{abstract}
The need to develop teaching methodologies that are, in fact, efficient for the construction of knowledge is indisputable. In this perspective, there are indications in the literature that the cooperative learning methodology is configured as a viable alternative, which contributes to greater interaction between those involved and the development of social and cognitive skills. Thus, this work aims to analyze the perception of high school students in relation to the contributions of that methodology, outlining its positive and negative points. Data collection took place through the application of previously structured questionnaires following the ethical criteria of the research, in 1st and 3 rd year classes, comprising a sample of 42 students, whose participation was voluntarily. The results obtained show that the vast majority of students are in favor of the teaching methodology in question, classifying it as a determinant for their learning process, as it improves school performance and promotes the socialization of knowledge. Therefore, it is concluded that despite the problems mentioned by some students, the use of the cooperative methodology promotes greater interaction among students, with significant results in increasing school performance and in the acquisition of social skills.
\end{abstract}

Keywords: Active methodology; Teaching-learning; Students; Cooperative learning.

\title{
Resumen
}

Es indiscutible la necesidad de desarrollar metodologías de enseñanza que sean, de hecho, eficientes para la construcción del conocimiento. En esta perspectiva, existen indicios en la literatura de que la metodología de aprendizaje cooperativo se configura como una alternativa viable, que contribuye a una mayor interacción entre los involucrados y al desarrollo de habilidades sociales y cognitivas. Así, este trabajo tiene como objetivo analizar la percepción de los estudiantes de secundaria en relación a los aportes de esa metodología, destacando sus puntos positivos y negativos. La recolección de datos se realizó mediante la aplicación de cuestionarios previamente estructurados siguiendo los criterios éticos de la investigación, en las clases de 1er y 3er año, conformando una muestra de 42 estudiantes, cuya participación fue voluntaria. Los resultados obtenidos muestran que la gran mayoría de los estudiantes están a favor de la metodología de enseñanza en cuestión, calificándola como determinante para su proceso de aprendizaje, ya que mejora el desempeño escolar y promueve la socialización del conocimiento. Por lo tanto, se concluye que a pesar de los problemas mencionados por algunos estudiantes, el uso de la metodología cooperativa promueve una mayor interacción entre los estudiantes, con resultados significativos en el aumento del rendimiento escolar y en la adquisición de habilidades sociales.

Palabras clave: Metodología activa; Enseñanza-aprendizaje; Estudiantes; Aprendizaje cooperativo. 


\section{Introdução}

Uma das mais significativas discussões sobre os aspectos que integram o processo de ensino-aprendizagem envolve a necessidade de desenvolvimento de metodologias educacionais que sejam, de fato, construtoras do saber, visto que, a relação vertical e hierárquica adotada no tradicionalismo torna-se cada vez mais obsoleta no que se refere à aquisição de conhecimento.

Segundo Cunha e Uva (2016), a escola apresenta um papel fundamental na formação das novas gerações, sendo indispensável definir estratégias convenientes para a promoção e estímulo de aprendizagens mais efetivas, considerando as novas metodologias de trabalho que se voltam às relações sociais e privilegiam valores de solidariedade, partilha e ajuda.

A aprendizagem cooperativa consiste na utilização de pequenos grupos de alunos que trabalham juntos para maximizar sua própria aprendizagem e a dos colegas. Essa estratégia de ensino procura formar pessoas mais comprometidas, solidárias e menos competitivas. Quanto mais se pesquisa e se conhece a cerca dessa metodologia cooperativa, mais se evidenciam os seus resultados positivos (Johnson et al, 1999).

De acordo com Bitu (2014), numerosos estudos demonstram que a metodologia da aprendizagem cooperativa favorece uma relação positiva entre alunos e professores, além de promover também efeitos positivos no desenvolvimento de competências sociais, ampliando a capacidade de comunicação, o espírito de equipe, a flexibilidade, a adaptação à mudança, e o bem-estar psicológico, contribuindo ainda, para elevar a autoestima e a estabilidade emocional.

A aprendizagem cooperativa diferencia-se das outras metodologias por possibilitar ao aluno exercer um papel mais ativo em seu processo de aprendizagem, cujas atividades são desenvolvidas por grupos heterogêneos. Dessa forma, a aprendizagem passa a ser construída mediante um conjunto de interações sociais e culturais estabelecidas entre os membros de um grupo heterogêneo, condições que estimulam a discussão e a partilha de ideias entre os pares na procura de solução de problemas, o que, por sua vez, contribui para o aumento dos processos mentais mais elevados, como o raciocínio, a abstração e o pensamento crítico (Andrade, 2011).

É importante que as ações possibilitadas pelo ensino cooperativo possam ser pensadas, de modo que, os membros de um grupo possam ter um maior aproveitamento no que se refere ao aprendizado, cujo objetivo principal deva ser a geração e propagação do conhecimento entre os pares (Pereira; Silva, 2018). Assim, ao assumir um papel mais ativo, ao trabalharem em cooperação com os seus pares, os alunos podem desenvolver e dominar competências cognitivas e sociais que favoreçam o seu desenvolvimento integral, ao contrário de um ensino transmissivo em que o aluno desempenha um papel mais passivo no processo de aprendizagem, refletindo-se muitas vezes na desmotivação e no insucesso escolar (Moreira, 2012).

Para Vieira e Ciasca (2019), a aprendizagem cooperativa enquanto metodologia no contexto escolar tem crescido muito com o passar dos anos em muitos países, porém no Brasil, ainda é incipiente a sua utilização nas salas de aula, em todos os níveis. Como isso, percebe-se a necessidade de estudos que venham a contribuir para o seu conhecimento no contexto das possíveis aplicações educacionais.

Ciente da relevância da metodologia cooperativa para a estruturação dos saberes e desenvolvimento de competências sociais, faz-se necessário melhor conhecer os seus aspectos básicos e suas contribuições no contexto escolar. Com isso, surge o questionamento impulsionador dessa pesquisa: De que forma os alunos percebem essa metodologia no contexto da sala de aula?

Diante do que foi exposto, o presente trabalho tem como objetivo analisar a percepção de alunos do ensino médio em relação à contribuição da metodologia cooperativa para o seu aprendizado, delineando os pontos positivos e negativos da sua aplicação em sala de aula, e considerando o papel do professor e a interação de cada um em seus grupos de estudos, de modo que os resultados obtidos possam servir de base para o alcance de melhorias na qualidade do ensino-aprendizagem. 


\section{Características, Princípios Teóricos e Metodológicos da Aprendizagem Cooperativa}

A aprendizagem cooperativa (AC) tem como um dos principais objetivos contribuir para o desenvolvimento dos alunos, mas isso só é possível quando, de fato, estes atuam em cooperação e são capazes de potencializar as vantagens que o trabalho em grupo proporciona. Os alunos, assim como necessitam aprender os conteúdos curriculares, também precisam das competências sociais, em especial, aquelas associadas ao trabalho em pequenos grupos, que em alguns casos consistem em competências interpessoais genéricas, mas que de qualquer modo envolvem uma certa especificidade do contexto das relações escolares (Tomé et al, 2004).

A referida metodologia desenvolve competências sociais, e assim, contribui para a efetivação de aprendizagens significativas, desde que se entenda e se pratique o verdadeiro sentido de cooperar. Essa estratégia oferece muitas vantagens para os alunos como, aumento de seu rendimento e a melhoria da autoestima (Pinho et al, 2013).

Apesar de não ser possível estabelecer com precisão quais os pioneiros no uso da aprendizagem cooperativa no ambiente escolar, pesquisas apontam que o movimento pedagógico cuja metodologia seja base tenha tido a sua origem nos Estados Unidos da América, embora existam experiências semelhantes na mesma época no Canadá, Israel, Austrália, e também na Europa, sobretudo na Inglaterra (Magalhães, 2014).

Essa metodologia vem sendo objeto de muitos estudos voltados para a educação, decorrente disso, Johnson et al (1998) afirma que para proporcionar um solo rico para aprendizagem cooperativa, existem algumas teorias que predizem que essa forma de aprendizagem promove um desempenho maior do que a aprendizagem competitiva ou individualista.

Segundo os mesmos autores, a AC tem suas raízes na criação das teorias: interdependência social, cognitivo-evolutiva e aprendizagem comportamental. A primeira vê a cooperação como resultante da interdependência positiva entre os alvos dos indivíduos, cuja premissa básica é que o modo como a interdependência social é estruturada determina o modo como os indivíduos interagem, que, por sua vez, determina os resultados. A teoria cognitivo-evolutiva vê a cooperação como um prérequisito essencial para o crescimento cognitivo, a qual flui da coordenação de perspectivas à medida que os indivíduos trabalham para atingir alvos em comum. Nesta teoria, Piaget e Vygotsky afirmam que trabalhar de modo cooperativo com parceiros e instrutores mais capazes resulta em desenvolvimento cognitivo e em crescimento intelectual. Já a teoria da aprendizagem comportamental pressupõe que a aprendizagem cooperativa é planejada para fornecer incentivos aos membros de um grupo a fim de que eles participem no esforço do grupo.

Os esforços cooperativos vêm evoluindo nesses últimos anos, e elegeram cinco elementos importantes para definir uma aprendizagem cooperativa: Interdependência Positiva; Responsabilidade Individual; Interação Promotora (face a face); Habilidade Social e Processamento de Grupo (Johnson et al, 1998).

Além desses pressupostos a $\mathrm{AC}$ considera ainda três outros aspectos: a motivação, a coesão social e a cognição. O primeiro aspecto pode ser resumido na ideia de que os membros do grupo só conseguem realizar seus objetivos se o grupo for bem-sucedido, ou seja, para se ter uma recompensa final (o sucesso), todos necessitam ajudar a todos. De igual modo, a cooperação tende a promover uma autoestima mais elevada. Os membros de grupos cooperativos se tornam mais habilitados socialmente em relação àqueles submetidos a outras metodologias e, quanto mais trabalharem juntos, maior será sua saúde psicológica em geral. Isso tem relação com o segundo aspecto, a coesão social, visto que se parte da prerrogativa de que utilizar a AC não é somente favorecer o "estar junto", mas estimular cada sujeito a ajudar um ao outro (Bello et al, 2018).

Sobre o aspecto da cognição referido acima, de acordo com Nitzke e Franco (2002), para que a aprendizagem cooperativa realmente aconteça, no sentido de um desenvolvimento cognitivo provocado por interações, argumentações, negociações, desequilíbrios e reequilíbrios ocorridos durante a realização de um trabalho conjunto, é necessária uma concepção de aprendizagem diferente das teorias baseadas na passividade do aprendiz. 


\section{Relação entre a Aprendizagem Cooperativa e a Concepção Construtivista de Ensino-Aprendizagem}

O estudo da implementação em salas de aula de métodos alternativos, tais como a aprendizagem cooperativa, teve como base a teoria do construtivismo social de Vygotsky, que foi o primeiro autor a diretamente conceber e idealizar a aquisição de conhecimento como sendo um processo longo e intrincado, balizado e modelado pelo ambiente sociocultural no qual a criança está inserida. Ele considerava que o meio social que rodeia os seres cognitivos é fundamental para o seu desenvolvimento e aprendizagem (Costa, 2015).

A Aprendizagem Cooperativa herda muito da perspectiva construtivista, ao promover "tarefas comuns" entre os grupos de trabalho; "engajamento social" pela preocupação com o outro; "conversações", em processo dialógico, com "membros mais experientes", ou, pelo menos, um processamento do grupo com experiências diferentes, que são trocadas dialogicamente, em uma proposta de organização articulada pelo professor, mas praticada pelos estudantes (Silva \& Gauche, 2009). Para tanto, a aprendizagem em sala de aula a partir dessa perspectiva requer atividades práticas bem elaboradas e que, portanto, desafiem as concepções prévias do aprendiz, encorajando-o a reorganizar suas teorias pessoais (Driver et al, 1999).

O construtivismo, seja inspirado nos estudos de Piaget ou de Vygotsky, reconhece as faces intra e interpsicológica do fenômeno da aprendizagem, definindo-a como processo de autoria empreendido pelo sujeito aprendiz (VASCONCELOS; Manzi, 2017). Partindo-se desse pressuposto, Nitzke e Franco (2002) destacam que as interações sociais seriam as principais desencadeadoras do aprendizado, nas quais, o processo de mediação se estabelece quando duas ou mais pessoas cooperam em uma atividade (interpessoal), possibilitando uma reelaboração (intrapessoal).

Os estudos de Piaget e Vygotsky influenciaram enormemente o desenvolvimento da metodologia de aprendizagem cooperativa, por atribuírem um papel determinante à interação social no desenvolvimento cognitivo (Menezes et al, 2007).

A Aprendizagem Cooperativa atua como caminhos determinantes à construção do conhecimento. Para Vasconcelos e Manzi (2017), os conflitos, a negociação, as demandas de cooperação e a própria comunicação são motivos à reconstrução ou reelaboração de esquemas prévios presentes na estrutura cognitiva do indivíduo.

Em sua história de vida, Freire e Freinet lutaram pela sobrevivência de seus ideários educacionais e sociais, que os tornaram defensores de uma educação cuja espinha dorsal é uma metodologia pautada na conscientização, no diálogo, na cooperação e na atividade, fazendo do educando sujeito das suas aprendizagens e cidadão do mundo. E do professor, um mediador nesse processo por meio de técnicas que favoreçam as interações (Gumiero \& Araújo, 2019).

\section{Metodologia cooperativa e a aprendizagem significativa}

A metodologia cooperativa envolve importante relação com a aprendizagem significativa, pois segundo Miranda, Barbosa e Moisés (2011), esta forma de aprendizagem se configura nas propostas de redirecionamento da relação professor/aluno, onde a figura do professor cede espaço a do facilitador e a aprendizagem ocorre a partir das vivências experimentadas pelo aluno.

Segundo Magalhães (2014), se bem trabalhada, a metodologia cooperativa favore o desenvolvimento de uma aprendizagem significativa, uma vez que fomenta a participação do aluno, estimula sua capacidade crítica e de argumentação em meio aos grupos, nos quais as discussões coletivas acerca dos conceitos e a introdução das vivências enriquecem a aprendizagem de todos.

Conforme Moura (2018), a aplicação da metodologia cooperativa procura proporcionar uma aprendizagem que não se baseie no acúmulo de conhecimento, mas que permita a interpretação, integração, modificação e estabelecimento de relações de coordenação entre esquemas de conhecimento já adquirido. E que a passividade não tenha espaço frente ao objeto de estudo, mas que a aprendizagem seja um processo, no qual o aluno constrói seus saberes com a ajuda do professor e em diálogo com os colegas, desenvolvendo também outras competências essenciais à vida em sociedade. 
Uma valiosa lista de razões justifica a importância do trabalho em pequenos grupos, razões estas como, as contribuições com a vida relacional ou emocional, o benefício cognitivo e o próprio valor que há em aprender a trabalhar em grupo. Dessa forma, a metodologia cooperativa pode ser vista como uma ferramenta para orientar o professor na utilização do trabalho em grupo não apenas como um facilitador do trabalho escolar, mas também como uma estratégia que vise à formação integral do ser humano (Menezes et al, 2007).

\section{O Papel do Educador no Contexto da Aprendizagem Cooperativa}

Um desafio permanente do educador refere-se à motivação dos educandos, sendo, portanto, a elaboração de estratégias para esse alcance, o principal papel do docente na atualidade. Nessa perspectiva, o educador encontra amparo em abordagens que referendam a importância do desenvolvimento de competências sociais para interação, especialmente, com os colegas, e para isso, elencam habilidades requeridas como, a escuta, aguardar o momento oportuno de falar, a capacidade de promover e compartilhar ideias, a disposição para ajudar o outro no sentido da formação de indivíduos críticos, ativos e engajados com a sociedade, habilidades estas possibilitadas pela metodologia cooperativa, e também referenciadas pela pedagogia freiriana (Silva et al, 2016).

De acordo com Ludovino (2012), no processo ensino-aprendizagem dito tradicional o professor tem um papel fundamental envolvendo-se num método de ensino, sobretudo, expositivo, em que ele é a autoridade principal responsável por repassar o conteúdo, não instigando assim, o lado crítico e social do aluno. Contrastando com este cenário, quando se aplica a estratégia da aprendizagem cooperativa em sala de aula, o professor passa a assumir um papel inteiramente diferente, para o qual deve existir um equilíbrio na atuação entre professor e alunos, a fim de que estes não sejam passivos, mas ativos e comprometidos com esse processo.

Johson et al (1999) menciona que o professor deverá seguir três regras muito simples para que o resultado final da aplicação da aprendizagem cooperativa seja benéfico para os alunos. Em primeiro lugar, deve se programar e definir bem quais competências pretende que sejam desenvolvidas; em segundo deve-se projetar aulas cooperativas de maneira que não sobrecarregue os alunos exigindo que seja feito determinada coisa em um curto tempo, respeitando assim o seu tempo; e em terceiro, é importante estimular que os alunos pratiquem as competências sociais que foram desenvolvidas nos trabalhos em grupos, até que eles as exerçam de forma involuntária e com frequência.

Conforme Teixeira (2012), o mais importante para um professor deve ser a sua preocupação em abrir portas, possibilitar o conhecimento pelas experiências, mais do que explicar e fechar questões. E sobre essa necessidade, Silva e Gauche (2009) afirmam que na Aprendizagem Cooperativa, observa-se a ampliação dos limites da competência educativa com a maior responsabilidade, por parte dos alunos, pela aprendizagem individual e dos colegas do grupo, alcançando assim, objetivos cognitivos, emotivos e sociais.

Com isso, entende-se que a sociedade necessita de mais relações cooperativas, e a sala de aula é um ambiente frutífero para se propor uma metodologia que favoreça tais relações. Contudo, é imprescindível maior investimento na formação continuada dos professores, para que, nesse sentido, o repertório de alternativas pedagógicas com essa abordagem se multiplique (Silva \& Gauche, 2009).

As salas de aula são lugares onde a interação social em grupos é vista como algo que fornece o estímulo de perspectivas diferentes, sobre as quais, os indivíduos passam a refletir. Assim, o papel do professor é fornecer as experiências físicas necessárias e encorajar a reflexão (Driver et al., 1999). Nesse contexto de ressignificação, a prática docente não é neutra. Pelo contrário, educar é um ato político, onde a superação do senso comum se opera no afrontamento, na análise crítica e intervenção social (Vasconcelos \& Manzi, 2017). 


\section{Metodologia}

\section{Caracterizações da Pesquisa}

Esta pesquisa, apesar de ter um tratamento quantitativo apresenta uma abordagem que se caracteriza, principalmente, na forma qualitativa (Pereira et al, 2018) com caráter descritivo e exploratório acerca da percepção de alunos do ensino médio sobre a Aprendizagem Cooperativa, cujo procedimento técnico consistiu em estudo de caso.

Segundo Silveira e Córdova (2009), a abordagem qualitativa preocupa-se com o aprofundamento da compreensão de um grupo social. André (2013, p. 97), pontua que pesquisas dessa natureza "se fundamentam numa perspectiva que concebe o conhecimento como um processo socialmente construído pelos sujeitos nas suas interações cotidianas, enquanto atuam na realidade, transformando-a e sendo por ela transformados".

Quanto ao caráter descritivo da pesquisa, Gil (2002) afirma que esse tipo de estudo se volta à descrição das características de determinada população ou fenômeno ou, então, ao estabelecimento de relações entre variáveis, sendo uma de suas características mais significativas a utilização de técnicas padronizadas de coleta de dados, tais como o questionário e a observação sistemática.

Já a pesquisa do tipo exploratória proporciona maior familiaridade com o problema, com vistas a torná-lo mais claro ou a constituir hipóteses, podendo-se dizer que se volta ao aprimoramento de ideias ou a descoberta de intuições (Gil, 2002). Estudos com essa finalidade habitualmente envolvem levantamento bibliográfico e documental, bem como estudos de caso (Gil 2008).

Com relação ao procedimento de pesquisa que consiste em um estudo de caso, trata-se de uma investigação empírica que estuda um fenômeno contemporâneo em profundidade dentro de seu contexto da vida real, especialmente quando os limites entre o fenômeno e o contexto não são claramente definidos (Yin, 2001). De modo geral, é de um tipo de pesquisa de campo que busca o entendimento da realidade sobre determinado tema focando uma ou várias unidades de análise (Marques et al, 2015).

\section{Campo Social e Sujeitos da Pesquisa}

A pesquisa foi desenvolvida em uma Escola de Ensino Médio pertencente à rede estadual de ensino do Ceará, localizada na zona urbana do município de Milagres - CE, cujos dados principais foram coletados no segundo semestre de 2017, a partir de quando vieram sendo conduzidas as demais etapas necessárias para materialização desse trabalho de conclusão de curso.

Situada no sul do estado do Ceará, a Cidade de Milagres dista $501 \mathrm{~km}$ da capital - Fortaleza, e se destaca por ser a segunda cidade com uma subestação CHESF - Companhia Hidroelétrica do São Francisco, responsável pela distribuição de energia no Nordeste.

O referido trabalho iniciou-se impulsionado pela disciplina Pesquisa Educacional para as Ciências Biológicas, que integra a matriz curricular do Curso de Licenciatura em Ciências Biológicas, na qual um dos requisitos foi o desenvolvimento de um estudo que se voltasse à abordagem do contexto escolar, podendo-se considerar para o estudo seus variados elementos e características.

A escola, objeto da pesquisa, oferta ensino médio na modalidade regular, e vem desenvolvendo suas funções educacionais desde 1979, ano de sua criação e funcionamento, quando inicialmente foi denominada como Escola de $1^{\circ}$ grau, anos depois tornou-se de $1^{\circ}$ e $2^{\circ}$ graus, mas a partir de 1997 passou a assumir a denominação de Escola de Ensino Médio (EEM).

De acordo com o projeto político pedagógico (PPP) da instituição, sua metodologia de ensino-aprendizagem é apontada como sendo a Aprendizagem Cooperativa, e registra-se a presença da modalidade de Atendimento Educacional 
Especializado (AEE). O referido documento afirma que a escola atende um público de 501 adolescentes e jovens, sendo estes de situação econômica e social diversas, distribuídos em 14 turmas e dois turnos: matutino (07 turmas), vespertino (07 turmas). O quadro de docentes conta com 19 professores em sala de aula, e sua organização curricular é feita através de disciplinas, das quais $72,2 \%$ são da Base Nacional Comum, e 27,8\% da Parte Diversificada como, inglês e Espanhol, Formação para a Cidadania, Iniciação à Pesquisa, Mundo do Trabalho e Tecnologias da Informação e Comunicação - TICs.

Em relação à sua estrutura física, a instituição possui ambientes pedagógicos como: uma Biblioteca e/ou Sala de Leitura, Laboratório de Informática, Laboratório de Ciências e Laboratório de Humanas, sete salas de aula, uma sala para a equipe pedagógica/professores, uma sala para atendimento educacional especializado (AEE), e uma quadra poliesportiva.

\section{Procedimentos Utilizados para a Obtenção dos Dados}

Inicialmente, realizou-se estudos com base na bibliografia específica a fim de se inteirar sobre a temática e identificar suas bases conceituais para, assim, elaborar o instrumento para coleta das informações, bem como o referencial teórico. Com a pesquisa delineada, procurou-se a direção da escola pretendida para o estudo, para a qual se apresentou os objetivos e possíveis contribuições da mesma, bem como os procedimentos para coleta dos dados junto aos alunos.

A obtenção dos dados se deu a partir de duas turmas de ensino médio, cuja escolha foi aleatória, sendo uma de $1^{\circ} \mathrm{e}$ outra de $3^{\circ}$ ano, as quais perfizeram uma amostra de 42 alunos. Como instrumento de coleta, utilizou-se a aplicação de um questionário semiestruturado composto de 7 questões, previamente definidas, e que integraram perguntas de múltipla escolha e abertas. Tais questões se voltaram a caracterizar a Aprendizagem Cooperativa com base nas opiniões dos alunos participantes.

A ação da coleta de dados teve início na turma do $1^{\circ}$ ano, seguida pela turma do $3^{\circ}$, tendo duração média de $30 \mathrm{~min}$ em cada sala. É importante destacar que uma parte dos alunos do $1^{\circ}$ ano não concordou em participar, apenas 19 participaram. No $3^{\circ}$ ano encontravam-se presentes 23 alunos na turma, e todos se mostraram dispostos a contribuir com a pesquisa.

Atendendo aos aspectos éticos, todos os sujeitos foram devidamente esclarecidos acerca dos objetivos e possíveis contribuições da pesquisa, enfatizando-se sua participação como voluntária, destacando a livre opção em aceitar ou não participar, e assegurando-se a privacidade de sua identidade em todas as etapas da pesquisa, condicionando sua participação à assinatura do Termo de Consentimento Livre e Esclarecido - TCLE (Apêndice A), conforme preconiza a Resolução 510/2016 do Conselho Nacional de Sáude (CNS).

\section{Procedimento para Análise e Discussão dos Dados}

Em relação aos resultados obtidos pelas questões de múltipla escolha, estes foram tabulados em planilhas do Microsoft Excel 2010, a partir das quais foram elaborados gráficos percentuais para melhor representação das informações e análises.

Para o tratamento das questões abertas, procedeu-se a sistematização das informações registradas, inicialmente transcrevendo-as, de acordo com as respostas obtidas para cada pergunta, e dispondo-as em tabelas, de forma sequenciada, a fim de possibilitar a leitura geral e uma melhor visualização dos resultados. Para análise, seguiu-se o método da análise de conteúdo recomendado por Bardin (2004), cuja aplicação permite alcançar, por condensação, uma representação simplificada dos dados brutos, o que possibilita a identificação de similaridades nos aspectos evidenciados em cada temática, resultando no conhecimento de elementos que não ficam tão claros nos discursos, antes de feita essa análise.

Para o tratamento dos participantes, a fim de preservar a sua identidade, estes foram designados pela inicial $\mathrm{P}$ (Participante), seguida por algarismo numérico - 1, 2, 3.. (ex. P.1 = Participante 1). E os resultados após analisados foram discutidos com base na literatura disponível sobre a temática. 


\section{Resultados e Discussão}

Com base nas informações obtidas com a aplicação dos questionários, foi possível analisar os principais aspectos da Aprendizagem Cooperativa na perspectiva de alunos do ensino médio, bem como avaliar os pontos positivos e negativos da mesma, buscando compreender sua contribuição para o desenvolvimento pessoal dos alunos, convívio social e construção de conhecimento. Os resultados apresentados a seguir, foram obtidos a partir das questões de múltipla escolha, e na sequência destes, estão dispostos os achados referentes à aplicação das perguntas abertas.

A princípio, foi solicitado que os participantes comparassem a metodologia de ensino tradicional com a metodologia cooperativa e mencionassem a mais favorável para o aprendizado. Em resposta, a grande maioria (83\%) citou a cooperativa como mais produtiva, alegando que o trabalho em grupo facilita a aprendizagem, uma vez que, se sentem mais motivados e podem compartilhar com os colegas as dúvidas, dificuldades e também as contribuições para a construção de conhecimento. Uma pequena parcela de apenas $17 \%$ dos participantes afirmou preferir o ensino tradicional, justificando que o trabalho em grupo, por vezes, atrapalha o desempenho (Gráfico 1).

Gráfico 1. Percepção dos alunos sobre a melhor metodologia de ensino-aprendizagem, entre a tradicional e a cooperativa.

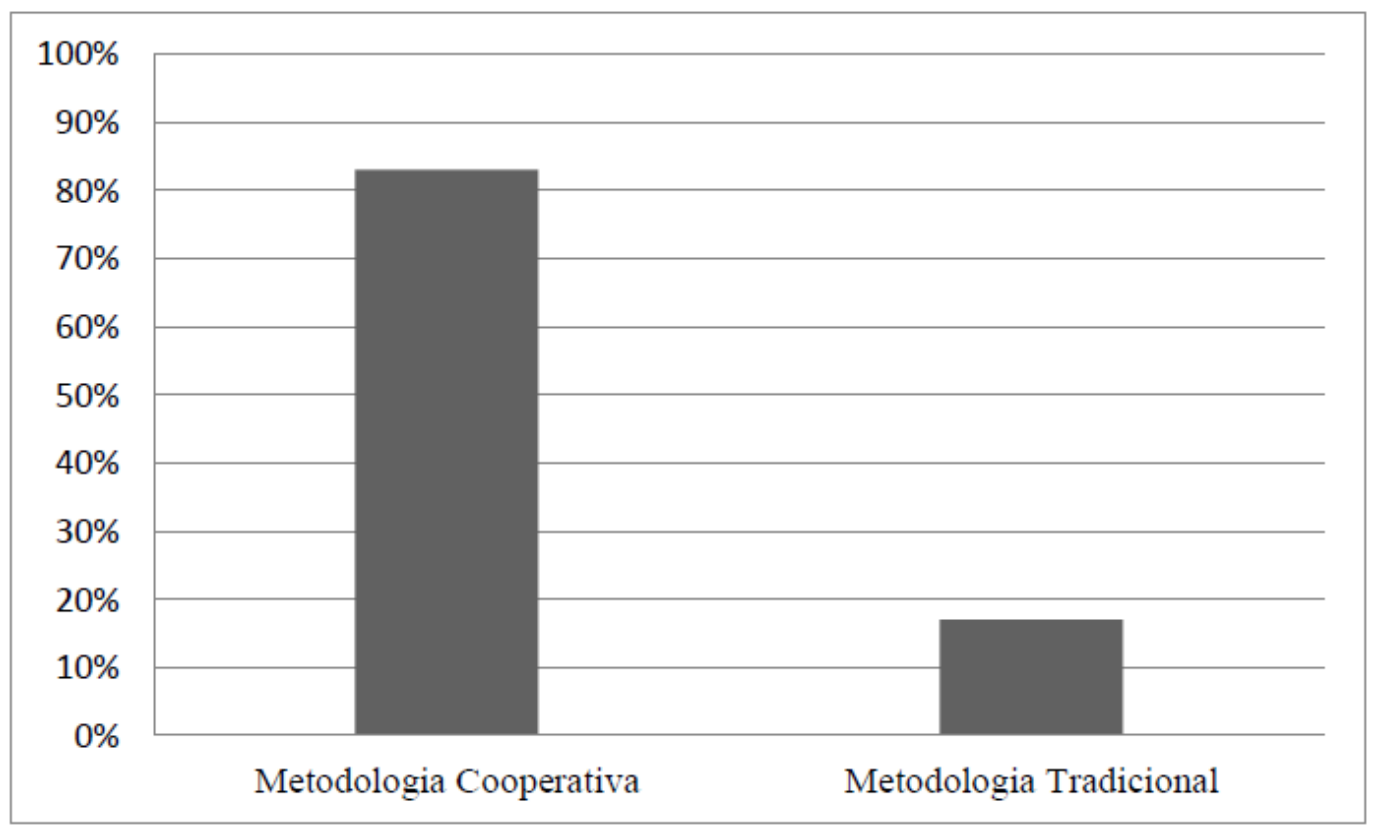

Fonte: Autores (dados da pesquisa).

A expressividade observada nas respostas demonstra uma grande afinidade por parte dos alunos pela metodologia cooperativa, corroborando com a ideia de Fuks (2000), de que o ensino tradicional vem perdendo espaço para a aprendizagem cooperativa, na qual não há confinamento e o aprendiz escolhe o momento de interagir com o docente. De acordo com Firmiano (2011), essa estratégia permite uma maior interação dos estudantes com seus colegas, ao mesmo tempo em que demonstra resultados significativos no aumento do rendimento escolar e na aquisição de habilidades sociais.

Pereira e Sanches (2013) destacam que quando comparada com outras metodologias de ensino mais tradicionais, a aprendizagem cooperativa trabalha mais com os alunos os seus interesses e necessidades, apresentando muitas vantagens em níveis de compreensão, de alcance de conhecimento e responsabilidade comportamental.

No segundo questionamento, os alunos foram indagados quanto à interação entre os membros de seus respectivos grupos de estudo, podendo se posicionar diante de três categorias distintas, onde $31 \%$ classificaram como sendo excelente; $62 \%$ disse ser satisfatória, e apenas $7 \%$ afirmou ser insatisfatória. Portanto, considerando a influência mútua como quesito 
primordial para o alcance dos objetivos propostos, é perceptível que, no geral, esse aspecto é bem desenvolvido dentro do grupo investigado (Gráfico 2).

Gráfico 2. Apontamentos relativos à classificação da interação entre os membros a partir dos trabalhos em grupos.

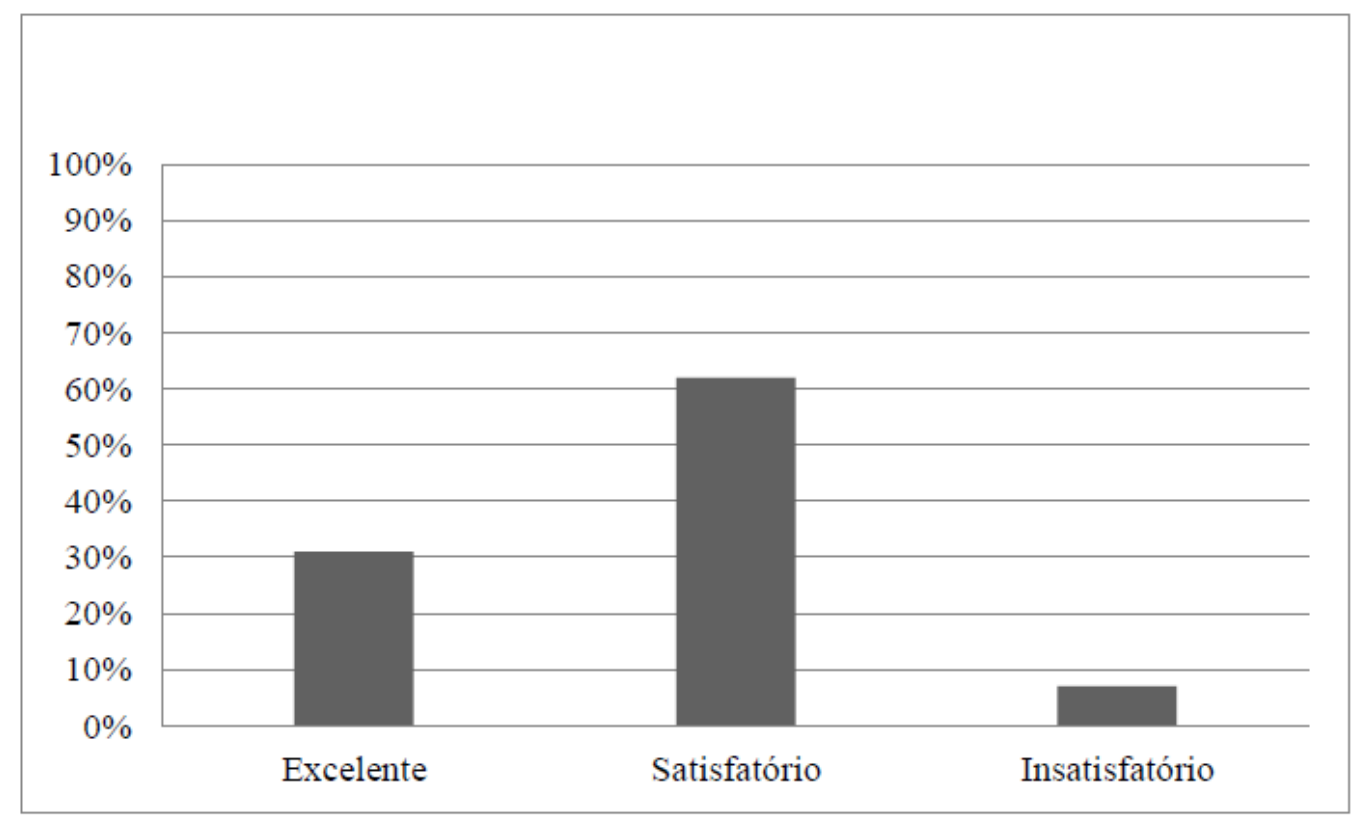

Fonte: Autores (dados da pesquisa).

Cunha e Uva (2016), afirmam que as interações proporcionadas pelos momentos de aprendizagem em grupo permitem desenvolver competências sociais e cognitivas, pois os alunos são desafiados a explicar as suas ideias, justificar ações e ajudar-se entre si para o alcance de objetivos comuns.

De acordo com Magalhães (2014), a partilha da aprendizagem em grupo vem sendo muito utilizada por professores e apontada pela pedagogia como detentora de infinitas vantagens na questão da melhor aprendizagem, contribuindo assim, no processo de formação do aluno em busca de desenvolver sua identidade pessoal e seu ser pensante.

Perguntou-se também aos alunos sobre as vantagens possibilitadas pelo desenvolvimento da metodologia cooperativa, e um percentual muito representativo dos alunos (95\%) mencionou a ajuda mútua, revelando assim que, o fato de poderem auxiliar os colegas e contar com eles quando necessário pode proporcionar melhorias na aprendizagem, uma vez que facilita a compreensão de conteúdos que não são esclarecidos apenas com explicações do professor. Outros alunos (5\%), não responderam.

Este dado agrega valor ao pensamento de Bitu (2014), quando descreve que o sentido da Aprendizagem Cooperativa é de que se estabeleça o espírito de parceria entre os alunos, de modo que os membros de cada grupo sejam responsáveis não somente em aprender o que é ensinado, mas também de ajudar os colegas a se apropriarem do conhecimento. Além disso, a autora coloca que os benefícios podem se estender ainda, a situações futuras de trabalho extraescolar, visto que, cada vez mais as atividades exigem pessoas que estejam aptas ao trabalho cooperativo.

Também segundo Tomé e Gomes (2004), a aprendizagem cooperativa apresenta muitas vantagens quando comparada com a aprendizagem tradicional, principalmente para os alunos, os quais ganham em motivação, melhoram sua interação entre seus pares, aprendem a partilhar e a respeitar o outro.

Quando solicitados que classificassem o modo de interação do professor com os diferentes grupos em sala de aula, os alunos se expressaram da seguinte forma: 50\% deles considerou como sendo excelente; $45 \%$ como satisfatória, e uma minoria 
de apenas 5\%, considerou como insatisfatória (Gráfico 3).

Diante do exposto, pode-se considerar que o professor desempenha um papel de extrema importância para o bom andamento dessa metodologia de ensino, visto que quando se propõe organizar trabalhos em grupo, à luz dos pressupostos teóricos da Aprendizagem Cooperativa, o mesmo deve estar ciente do seu papel de mediador, o qual inclui observações atentas com o intuito de planificar as atividades, proporcionar situações de ensino- aprendizagem que estimulem o aluno a respeitar as ideias e opiniões do outro, bem como a clara definição dos objetivos comuns para o grupo e as táticas para a sua realização, evidenciando-se as responsabilidades individuais e coletivas (Scheibel et al., 2009).

Gráfico 3. Considerações dos alunos acerca da interação do professor com os mesmos.

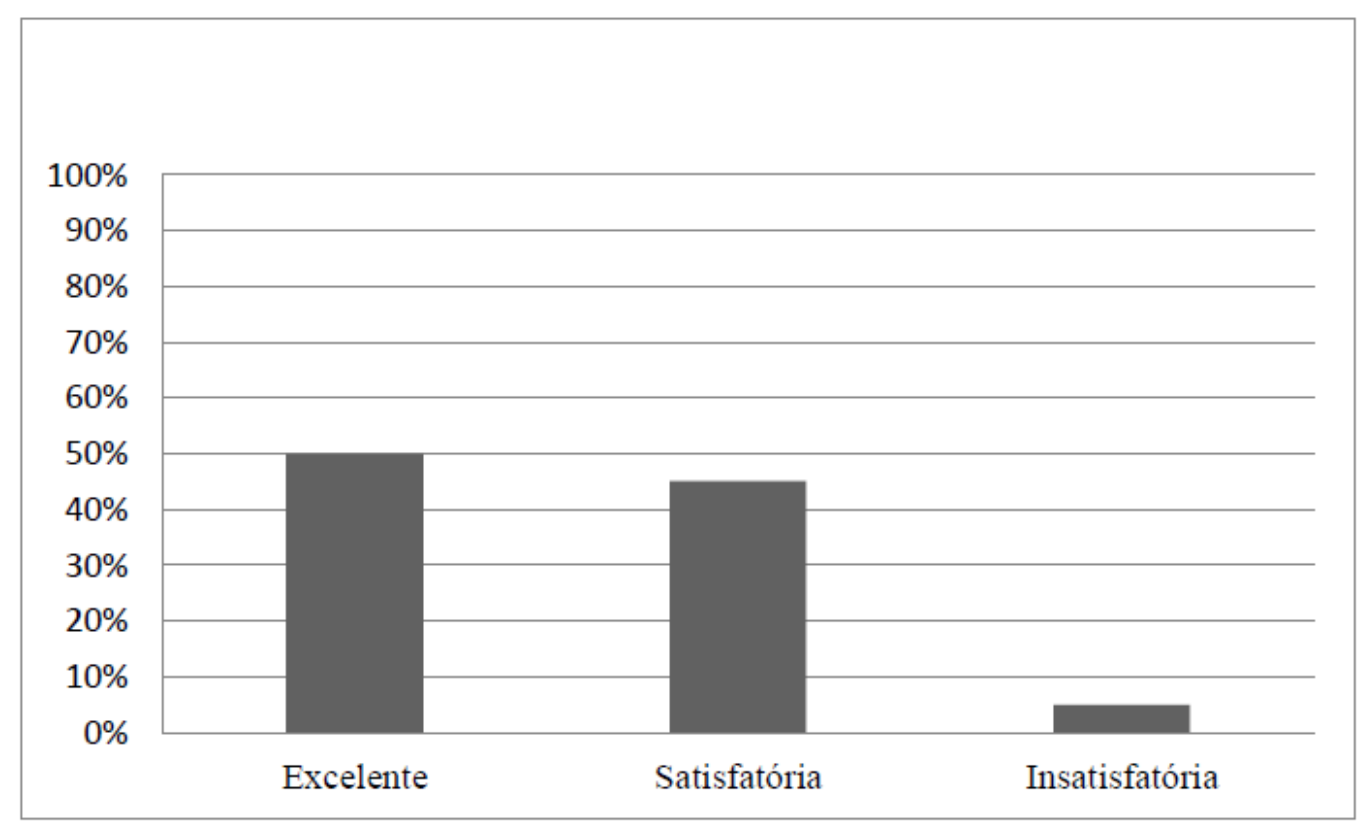

Fonte: Autores (dados da pesquisa).

O papel do professor hoje é muito mais amplo e inovador, visto que ele não está centrado só em transmitir as informações de uma disciplina específica; ele é, principalmente, design de roteiros personalizados e grupais de aprendizagem e mentor de projetos profissionais e de vida dos alunos (Moran, 2011). Espera-se que o professor seja capaz de adotar estratégias que permitam a construção de aprendizagens significativas, que adotem uma postura crítica de como fazer e quais os recursos necessários para atingir esse objetivo, ideia esta que deverá estar presente, por exemplo, quando se pensar em recorrer à metodologia da aprendizagem cooperativa (Magalhães, 2014).

Um outro questionamento apresentou uma lista com possíveis implicações da utilização da metodologia de aprendizagem cooperativa, a partir da qual os alunos foram solicitados a indicar quais eles já identificaram ou vivenciaram em seus respectivos grupos (gráfico 4).

Os resultados evidenciam que, mesmo com todos os benefícios já referendados pela bibliografia especializada, a Aprendizagem Cooperativa ainda apresenta elementos que precisam ser melhorados no que diz respeito a uma maior articulação por parte dos membros, para que haja de fato, resultados positivos em cada grupo de estudo. Diante disso Moran (2011), fala que a aprendizagem acontece num ambiente social que está cada vez mais complexo, dinâmico e imprevisível. A colaboração pode nos ajudar a desenvolver nossas próprias competências, mas também pode provocar momentos de tensões, desencontros, ruídos e decepções. 
Gráfico 4. Implicações da Metodologia Cooperativa na perspectiva dos alunos.

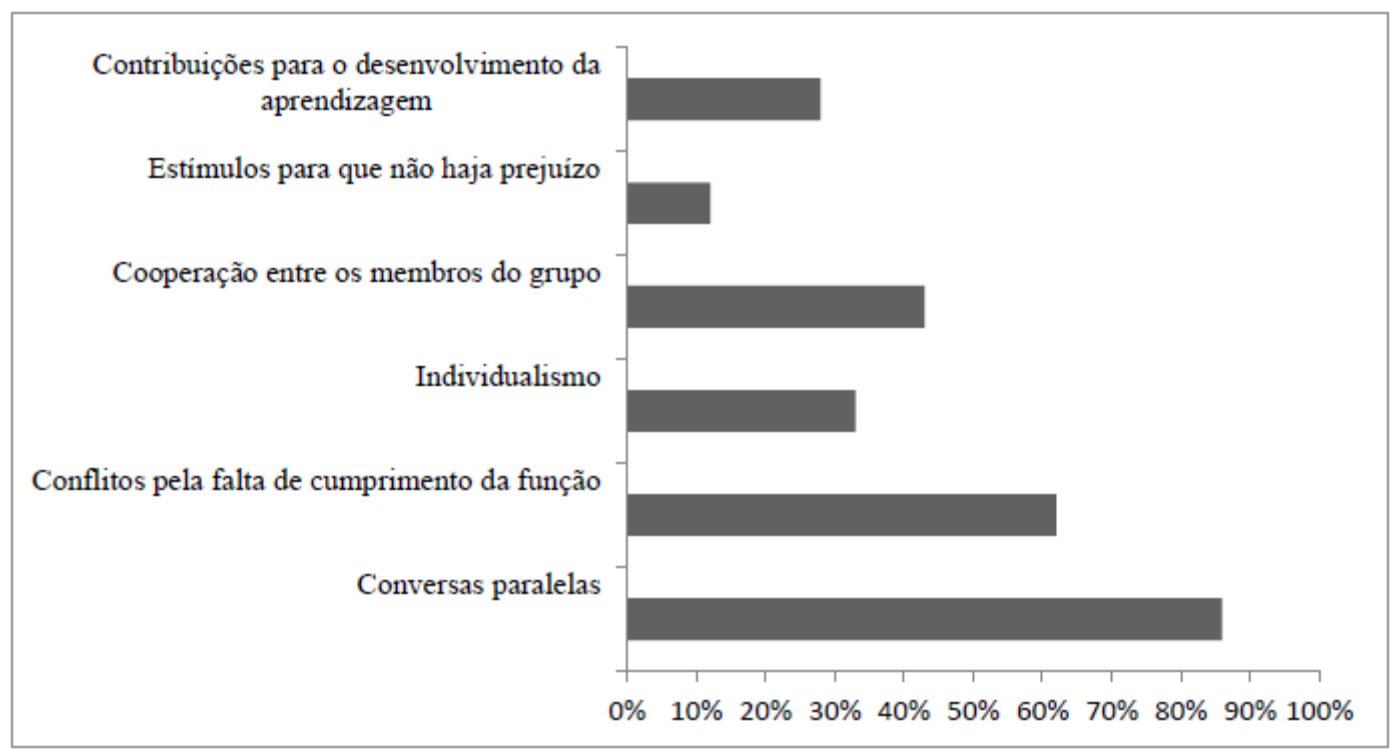

Fonte: Autores (dados da pesquisa).

Essa proposta de ensino não pode ser confundida com os trabalhos em grupo realizados dentro de uma abordagem mais tradicional de ensino, onde muitas vezes é percebido apenas um agrupamento físico de pessoas, sem que se atinja uma verdadeira aproximação a nível afetivo e psicológico, deixando a desejar em quesitos como interação, auxílio mútuo, cooperação e preocupação com o outro (Scheibel, et al., 2009). Aspectos estes que são determinantes para a construção dos saberes.

Sobre a aplicação das questões abertas, foram obtidas variadas informações decorrentes da livre expressão das ideias dos alunos referentes a alguns aspectos da Aprendizagem Cooperativa como, dificuldades e considerações acerca da experiência com tal metodologia. Dessa forma, tomou-se o conjunto das respostas dos alunos, as quais foram cuidadosamente analisadas para identificar as similaridades nas opiniões, categorizando-as através dos aspectos representativos, conforme apresentado abaixo.

Quando questionados sobre as dificuldades encontradas com a utilização da metodologia estudada, alguns alunos responderam que consideravam a falta de colaboração ou descumprimento das funções por partes de alguns membros do grupo; Outros falaram sobre as conversas paralelas e indisciplina; alguns responderam também sobre os problemas de convívio entre os membros do grupo relacionados à divergência de opiniões e individualismo; um pequeno número afirmou que não tinha dificuldade; e apenas um aluno não respondeu (Tabela 1).

Tabela 1. Percepção dos alunos sobre as dificuldades encontradas na Metodologia Cooperativa. Participantes: $1 ; 3 ; 6 ; 10 ; 14 ; 15 ; 16 ; 18 ; \quad$ Consideram a falta de colaboração ou descumprimento da função por parte de $19 ; 21 ; 22 ; 23 ; 31 ; 40$ alguns dos membros.

Participantes: $8 ; 11 ; 20 ; 25 ; 26 ; 27 ; 28 ; \quad$ Muitas conversas paralelas e indisciplina.

$30 ; 32 ; 35 ; 36 ; 37 ; 38 ; 39 ; 41 ; 42$

\begin{tabular}{ll}
\hline Participantes: $2 ; 5 ; 7 ; 12 ; 13 ; 17 ; 24$ & $\begin{array}{l}\text { Os problemas de convívio entre os membros do grupo relacionados à divergência } \\
\text { de opiniões e individualismo. }\end{array}$ \\
\hline Participantes: $4 ; 29 ; 34$ & Não tem nenhuma dificuldade. \\
\hline Participantes: 33 & Não respondeu.
\end{tabular}


Ainda sobre as dificuldades apontadas pelos alunos sobre a Aprendizagem Cooperativa, seguem descritas abaixo, alguns exemplos de falas registradas através dos questionários.

P.5 "Muitas das vezes não nos damos bem com os membros da célula".

P.10 "O fato que alguns colegas não fazem nada".

P.24 "Na maioria das vezes os colegas não estão dispostos a cooperar".

$P .35$ "A conversa que às vezes atrapalha".

P.40 "Quando algum dos alunos se rejeita a fazer a atividade orientada".

P.41 "As brincadeiras fora de hora".

Assim como acontece com outras estratégias de ensino, apesar dos muitos benefícios que são encontrados na Aprendizagem Cooperativa, há também apontamentos sobre algumas limitações, referidas em alguns trabalhos. Algumas dificuldades como, por exemplo, no que se refere a alunos com menos capacidade esperarem que os outros colegas desenvolvam o trabalho, ou até mesmo serem ignorados pelo restante dos membros (Magalhães, 2014).

Sobre os resultados referentes às dificuldades da Aprendizagem Cooperativa apontarem o distanciamento ou não envolvimento de alguns alunos com as atividades desenvolvidas em grupos, é válido ressaltar o que afirma Moreira (2012), que a interdependência positiva configura-se como um componente indispensável para o sucesso dos grupos na proposta da Aprendizagem Cooperativa, uma vez que, cada aluno deve ter consciência de que está ligado aos outros, de tal maneira que, não terá sucesso a não ser que os outros também o tenham.

Os problemas de convívio, conversas paralelas e indisciplina apontados por parte dos alunos como sendo limitações da aprendizagem em grupos, revelam-se como grande desafio aos docentes, os quais, segundo Pinho et al (2013) receiam perder o controle da aula, visto que os alunos passam a ter comportamentos mais ativos, além da necessidade de preparar materiais que, de fato, consigam promover o desenvolvimento de informações, mas que nem sempre dispõem de tempo necessário para fazer isso.

A outra questão aberta solicitou aos participantes que descrevessem sua opinião acerca da referida metodologia, com base em suas experiências em sala de aula. Observou-se que, a maioria dos alunos, considera a metodologia cooperativa como muito satisfatória, importante no seu desenvolvimento através de pontos como, ajudar os colegas em suas dúvidas, interagir

e trocar conhecimento. Outra parcela de alunos afirma que a metodologia tem seus pontos positivos, mas que alguns aspectos deixam a desejar, principalmente, em quesitos como à organização e cooperação entre todos os membros. E uma pequena parcela de alunos optou por não responder (Tabela 2).

Pelo exposto, a proposta da Aprendizagem Cooperativa leva a uma reflexão de como as atividades engajadoras e construtivas podem facilitar a aprendizagem, comprovando que quando há interação entre pessoas de forma colaborativa, por meio de uma atividade autêntica, cada pessoa envolvida consegue ver o problema de uma perspectiva diferente, sendo, portanto, aptas a negociar e gerar significados e soluções mediante um entendimento compartilhado (Torres \& Irala, 2014).

Pereira e Sanches (2013) ressalta que a aprendizagem cooperativa permite, então, que os alunos desenvolvam competências que vão muito além do domínio e reprodução dos conteúdos escolares ministrados pelo docente, assumindo-se como um método por excelência na promoção de competências de cooperação e colaboração. 
Tabela 2. Opinião dos alunos sobre a metodologia cooperativa com base em suas experiências.

Participantes: $1 ; 2 ; 3 ; 6 ; 8 ; 12 ; 24 ; 25$; Consideram que essa metodologia tem seus pontos positivos, no sentido de $26 ; 27 ; 28 ; 29 ; 31$ estimular o trabalho em grupo e de tirar as dúvidas dos colegas. Porém, deixa a desejar em alguns aspectos como, conversas paralelas, e principalmente, no que diz respeito à organização e cooperação entre todos os membros.

\begin{tabular}{ll}
\hline Participantes: $4 ; 5 ; 21 ; 32$ & Não responderam. \\
\hline Participantes: $9 ; 10 ; 11 ; 13 ; 14 ; 15 ; 16 ;$ & Consideram esta aprendizagem muito satisfatória, pois através dela tem-se a \\
$17 ; 18 ; 19 ; 20 ; 22 ; 23 ; 30 ; 33 ; 34 ; 35 ;$ & oportunidade de interagir, ajudar os colegas e trocar conhecimentos para a melhor \\
$36 ; 37 ; 38 ; 39 ; 40 ; 42$ & compreensão dos conteúdos. \\
\hline
\end{tabular}

Fonte: Autores.

P.6: "A aprendizagem cooperativa é uma metodologia que traz resultados satisfatórios, porém em alguns momentos podemos nos prejudicar por causa de outros".

P.28: "Na aprendizagem cooperativa a experiência é boa, mas existem conversas paralelas".

P.14: "Podemos aprender mais com os coleguinhas o que não sabemos e também compartilhar o que sabemos”.

P.23: "Muito boa, posso aprender com meus colegas e posso ensinar o que sei".

Entretanto, como visto nos apontamentos feitos por parte dos alunos, apesar destes reconhecerem os benefícios da metodologia, também ressaltam alguns aspectos que quando não bem definidos, interferem nos resultados do grupo, por exemplo, mencionam a questão da organização e cooperação. Assim, de acordo com Scherer e Brito (2014), torna-se necessário que o aluno seja corresponsável pela aprendizagem do outro, do grupo, sentindo-se parte desse, se posicionando, apresentando proposições sejam elas correspondentes, antagônicas ou complementares às dos colegas e do professor, na busca pela coordenação de ações externas e internas, para a compreensão do objeto em estudo.

\section{Conclusão}

Em virtude dos resultados anteriormente mencionados pode-se afirmar que, a metodologia cooperativa estimula o desenvolvimento de competências sociais e cognitivas, ao mesmo tempo em que possibilita aos alunos autonomia sobre seu próprio processo de aprendizagem e o desenvolvimento do conceito de responsabilidade, à medida em que estes se veem envolvidos no auxílio da aprendizagem do seu colega. Assim, a experiência decorrente dessa metodologia promove a socialização e integração do conhecimento, possibilitando habilidades comunicativas e estimulado a solidariedade dos educandos.

Os dados obtidos demonstram que a maioria dos alunos se posiciona a favor da metodologia em questão, classificando-a como eficiente para seu processo de aprendizagem, uma vez que ela melhora o rendimento escolar e promove a socialização do conhecimento. Somente uma pequena parcela do alunado classifica essa estratégia como falha, preferindo o uso de métodos tradicionais. Sobre as interações entre professor e alunos, e entre estes últimos e seus pares, constatou-se que, de modo geral, esse aspecto é bem desenvolvido. Isso se confirma, por exemplo, entre os alunos, quando estes, em grande maioria, apontam a ajuda mútua como sendo a principal vantagem da metodologia cooperativa.

Com relação às implicações da metodologia verificou-se que, para a maioria dos alunos, os conflitos pela falta de cumprimento da função e as conversas paralelas, figuram-se entre as principais limitações. Percebeu-se ainda, que o quesito converso paralelos aparece também quando os alunos são indagados sobre as dificuldades, sendo juntamente com a indisciplina, apontadas como as principais. 


\section{Considerações Finais}

Diante do exposto, é imprescindível que essa pesquisa ser ampliada a partir de novas contribuições, pois apesar de alguns pontos negativos mencionados por parte dos alunos sobre a aplicação dessa metodologia, não se pode negar a importância em desenvolvê-la, tendo em vista os variados benefícios proporcionados pela mesma. Entretanto, faz-se necessário uma reflexão acerca das suas falhas ou limitações, a fim de se definir melhorias para que possibilite o alcance de resultados ainda mais significativos no campo das aprendizagens e do desenvolvimento pessoal.

\section{Referências}

Andrade, C. D. N. R. (2011). Aprendizagem cooperativa: estudo com alunos do $3^{\circ}$ CEB (Doctoral dissertation, Instituto Polittécnico de Bragança, Escola Superior de Educação).

André, M. (2013). O que é um estudo de caso qualitativo em educação? Revista da FAEEBA, 22(40).

Bacich, L., \& Moran, J. (2018). Metodologias ativas para uma educação inovadora: uma abordagem teórico-prática. Penso Editora.

Bardin, L. (2004). Análise de conteúdo. Edições, 70, 223.

Bello, M. M. S., Capellini, V. L. M. F., \& Ribeiro, J. A. G. (2018). A Aprendizagem Cooperativa No Cenário Educacional Acadêmico Brasileiro. Nuances: estudos sobre Educação, 29(1).

Programa, D., \& Bitu, C. B. Aprendizagem Cooperativa: Uma Análise Da Escola Estadual De Educação Profissional Alan Pinho Tabosa.

Costa, J. P. A. (2015). Aprendizagem cooperativa: presença ou ausência no ensino das artes visuais em Portugal? (Master's thesis).

de Pinho, E. M., Ferreira, C. A., \& Lopes, J. P. (2013). As opiniões de professores sobre a aprendizagem cooperativa. Revista Diálogo Educacional, 13(40), 913-937.

Driver, R., Asoko, H., Leach, J., Mortimer, E., \& Scott, P. 1999.Construindo conhecimento científico na sala de aula. Tradução: Eduardo Mortimer. Química Nova na Escola, São Paulo, n. 9, p.31-40

Firmiano, E. P. (2011). Aprendizagem cooperativa na sala de aula. Programa de Educação em células cooperativas-PRECE.

Fuks, H. (2000). Aprendizagem e trabalho cooperativo no ambiente AulaNet. Revista Brasileira de Informática na Educação, 6(1), 53-74.

Gil, A. C. (2002). Como elaborar projetos de pesquisa (Vol. 4, p. 175). Atlas.

Gil, A. C. (2008). Métodos e técnicas de pesquisa social. (6a ed.), Ediitora Atlas SA.

Gumiero, R., \& de Araújo, K. (2019). Contribuições de Paulo Freire e Célestin Freinet ao processo de ensino-aprendizagem. Acta Scientiarum. Education, 41, e41255-e41255.

Johnson, D. W., Johnson, R. T., \& Holubec, E. J. (1999). El aprendizaje cooperativo en el aula.

Johnson, D., Johnson, R., \& Smith, K. (1998). A aprendizagem cooperativa retorna às faculdades. Change, 3(4), 91-102.

Ludovino, P. N. B. (2012). A aprendizagem cooperativa: uma metodologia a aplicar nas disciplinas de História e de Geografia.

Magalhães, A. M. C. (2014). A aprendizagem cooperativa enquanto estratégia para a promoção da atenção dos alunos: o caso de uma turma do 10ªno na disciplina de Economia (Doctoral dissertation).

Marques, K. C. M., Camacho, R. R., \& de Alcantara, C. C. V. (2015). Avaliação do rigor metodológico de estudos de caso em contabilidade gerencial publicados em periódicos no Brasil. Revista Contabilidade \& Finanças-USP, 26(67), 27-42.

Marques, S. P. D. (2013). Aprendizagem cooperativa como possibilidade de superação das dificuldades no aprendizado da química: o olhar dos educandos no ensino médio.

Marques, S. P. D., Ávila, F. N., Dias Filho, F. A., \& Silva, M. G. V. (2016). Aprendizagem cooperativa como estratégia no aprendizado de química no ensino médio. Conexões-Ciência e Tecnologia, 9(4), 57-66.

Menezes, M. G., Barbosa, R., \& Jófili, Z. (2007). Aprendizagem Cooperativa: O que pensam os estudantes. Linguagens, Educação e Sociedade, 17, 51-62.

Miranda, C. S. N. D., Barbosa, M. S., \& Moisés, T. F. D. (2011). A aprendizagem em células cooperativas e a efetivação da aprendizagem significativa em sala de aula.

Moreira, J. I. D. (2012). A aprendizagem cooperativa: Aplicação ao 8. ${ }^{\circ}$ ano de escolaridade na disciplina de História.

Moreira, M. A. (2000). Aprendizagem significativa crítica (critical meaningful learning). Teoria da Aprendizagem Significativa, 47. 
Research, Society and Development, v. 10, n. 8, e17410817166, 2021

(CC BY 4.0) | ISSN 2525-3409 | DOI: http://dx.doi.org/10.33448/rsd-v10i8.17166

Moura, F. A. N. (2018). Estudo de Caso "A Propaganda no Estado Novo": Uma abordagem de ensino/aprendizagem construtivista e cooperativa (Doctoral dissertation, Universidade de Coimbra).

Nitzke, J. A., \& Franco, S. R. K. (2002). Aprendizagem cooperativa: utopia ou possibilidade? Informática na educação: teoria \& prática. 5, 23-30.

da Silva, F. C. S., Alves, M. C., Bordoni, A. J., Takahashi, D. A. G., da Silveira, M. P., \& Kiouranis, N. M. M. (2019). Mitos e verdades: uma atividade avaliativa sobre uma sequência didática com o tema petróleo. Scientia Naturalis, 1(2).

Pereira, I. V., \& Silva, C. A. T. (2018). Aprendizagem cooperativa como estratégia de ensino para a contabilidade: Habilidades intelectuais da taxonomia do domínio cognitivo. Revista Ambiente Contábil-Universidade Federal do Rio Grande do Norte, 10(1), 54-70.

Pereira, A. S., Shitsuka, D. M., Parreira, F. J., \& Shitsuka, R. (2018). Metodologia da pesquisa cientifica. UFSM.

Pereira, M., \& Sanches, I. R. (2013). Aprender com a diversidade: as metodologias de aprendizagem cooperativa na sala de aula. Nuances: estudos sobre Educação, 24(3), 118-139.

Scheibel, M. R., Silveira, R. M. C. F., Resende, L. M., \& Júnior, G. S. (2009). Aprendizagem cooperativa: uma opção metodológica para se trabalhar as questões da ciência e da tecnologia nos cursos de formação de professores. Revista Brasileira de Ensino de ciência e tecnologia, 2(2).

Marques, S. P. D., Ávila, F. N., Dias Filho, F. A., \& Silva, M. G. V. (2016). Aprendizagem cooperativa como estratégia no aprendizado de química no ensino médio. Conexões-Ciência e Tecnologia, 9(4), 57-66.

Scherer, S., \& Brito, G. D. S. (2014). Educação a distância: possibilidades e desafios para a aprendizagem cooperativa em ambientes virtuais de aprendizagem. Educar em Revista, (SPE4), 53-77.

Silva, Â. J. D. (2007). Aprendizagem cooperativa no ensino de química: uma proposta de abordagem em sala de aula.

Silveira, D. T., \& Córdova, F. P. (2009). A pesquisa cientítica. Métodos de pesquisa. Editora da UFRGS, 33-44.

Teixeira, J. C. G. (2016). O contributo da Aprendizagem Cooperativa para o desenvolvimento do domínio curricular da escrita (Doctoral dissertation).

Valente, J. M. G. M. (2010). Trabalhar no grupo e com o grupo: uma estratégia para a inclusão de uma criança com Atraso Global do Desenvolvimento (Master's thesis). http://www.educ.fc.pt/docentes/ichagas/mi2/InesMarisaRogerioAvaliacao RevLitpdf

Torres, P. L., \& Irala, E. A. F. (2014). Aprendizagem colaborativa: teoria e prática. Complexidade: redes e conexões na produção do conhecimento. Curitiba: Senar, 61-93.

Vasconcelos, Y. L., \& Manzi, S. M. S. (2017). Processo ensino-aprendizagem e o paradigma construtivista. Interfaces Científicas-Educação, 5(3), 65-74.

Vieira, H. R., \& Ciasca, M. I. F. L. (2019). Contribuições da Aprendizagem Cooperativa na formação acadêmica e humana de graduandos da Universidade Federal do Ceará. Da Investigação às Práticas: Estudos de Natureza Educacional, 9(1), 114-128.

Yin, R. K. (2015). Estudo de Caso-: Planejamento e métodos. Bookman editora. 